\title{
Reading Lies: Nonverbal Communication and Deception
}

Aldert Vrij (University of Portsmouth, UK, aldert.vrij@port.ac.uk) ${ }^{1}$

Maria Hartwig (John Jay College of Criminal Justice, Graduate Center, CUNY, mhartwig@jjay.cuny.edu)

Pär Anders Granhag (University of Gothenburg, Sweden, pag@psy.gu.se)

\section{Key words}

Deception, Nonverbal behavior, deception, lie detection

${ }^{1}$ Correspondence concerning this article should be addressed to Aldert Vrij, Department of Psychology, University of Portsmouth, King Henry Building, King Henry 1 Street, PO1 2DY, Hants, United Kingdom. Email: aldert.vrij@port.ac.uk 


\begin{abstract}
The relationship between nonverbal communication and deception continues to attract much interest, but there are many misconceptions about this relationship. In this review we present a scientific view on the relationship. We describe theories explaining why liars would behave differently from truth tellers, followed by research how liars actually behave and people's ability to catch them. We will show that the nonverbal cues to deceit known to date are faint and unreliable, and that people are mediocre lie catchers when they pay attention to behavior. We will also discuss why people hold misbeliefs about the relationship between nonverbal behavior and deception - beliefs that appear very hard to debunk. We further discuss that researchers could improve the state of affairs by examining nonverbal behaviors in different ways and in different settings than they currently do.
\end{abstract}




\section{Reading others}

Life is so full of encounters with other human beings that we tend to take these encounters for granted. Often, social interactions run fairly seamlessly, and we do not spend much time reflecting on their omnipresence, or plumbing the depths of how they actually work. Scholars, however, have taken on the task of trying to understand social interaction in all its complexity. There is now a vast body of scientific literature on this topic spanning multiple disciplines, including psychology, sociology, anthropology, linguistics and philosophy.

When we interact with others, we make judgments of the other person's state of mind - we try to read their emotions, thoughts, needs and intentions. This makes sense, because knowing what is going on in another person's head can be used both to coordinate cooperative interactions, and to gain advantage in competitive ones.

A non-disputed claim in psychology is that mind reading (i.e., making inferences about another's state of mind) is central to social interactions. The psychological picture of humans painted by modern social and cognitive psychology is that of chronic mind readers, who constantly engage in rapid and partly automatic evaluation of the mental states of other people. How good are we then at accurately reading minds? The major finding from research is that we are not as good at reading other people as we think. We are not operating in complete darkness, but we vastly and consistently overestimate our skills (Epley, 2015). This is an arresting finding that cuts to the heart of our beliefs about ourselves as social agents.

\section{Reading deception and truth}

If mind reading is inaccurate in everyday life it might lead to confusion, misunderstandings and unnecessary conflict between individuals. Faulty mind reading 
can also have catastrophic consequences for individuals or for society as a whole. Deception is such an example where misjudgments can be costly. Nobody knows how many innocent people have suffered unjust punishment because others have judged them to be guilty, but we do know that this problem is substantial (Garrett, 2011; Scheck, Neufeld \& Dwyer, 2003). Thousands of people have died in terrorist attacks that could have been prevented if the deceptions involved to execute the attacks had been detected. So, in contrast to casual social judgments, judgments of deception and truth can literally be a matter of life and death.

There is an extensive body of work on deception and its detection. In this article we offer an overview and a critical discussion of this literature and focus hereby on the role of nonverbal behavior in telling and reading lies. We do so because, unlike verbal or physiological lie detection, judgements of nonverbal behavior can be made in every social encounter. Nonverbal lie detection is also a domain where many myths continue to exist: People typically overestimate the relationship between deception and nonverbal behavior and the ability to detect deceit by observing nonverbal behavior.

Two Annual Review of Psychology articles about deception proceeds this article. Hyman's (1989) theoretical contribution made us aware how much more deception research is published nowadays. Hyman covered the period $1966-1986$. Using SCOPUS search software with key words "lie detection" or "deception" we found 415 psychology articles for this period, an average of 20.75 per year. In the year 2016 alone we found 206 psychology articles, almost ten times as many. More recently, Pennebaker, Mehl, and Niederhoffer (2003) published an article that included deception, but it focused on word use rather than nonverbal behavior. In other words, this is the first Annual Review of Psychology article about nonverbal 
behavior and deception. We will provide a comprehensive overview and rely hereby on seminal publications in this field.

\section{Detecting deception through nonverbal behavior}

The notion that lies are transparent and can be detected through nonverbal behavior dates back a long time. As early as 900 B.C., it was claimed that liars shiver and engage in fidgeting behaviors (Trovillo, 1939a). In 1908, Münsterberg pointed to the utility of observing posture, eye movements, and knee jerks for lie detection purposes (Trovillo, 1939b). Famously, Freud (1959) wrote: “He who has eyes to see and ears to hear may convince himself that no mortal can keep a secret. If his lips are silent, he chatters with his finger-tips; betrayal oozes out of him at every pore” (p. 94).

Popular culture reflects the enduring belief that liars give themselves away through nonverbal behavior. For example, there are numerous books aimed at a popular audience recommending ways to decipher deception based on demeanor (e.g., Houston, Floyd and Carnicero, 2012; Meyer, 2010) Also, the basic mythology of the 'leaky liar' is integrated into American police interrogation manuals (Vrij \& Granhag, 2007). The belief in the detectability of lies is also built into many legal presumptions - for example, jurors in criminal cases are often asked to pay attention to the defendant's nonverbal behavior in order to assess their truthfulness (Sporer \& Schwandt, 2006; Vrij \& Turgeon, 2018).

The relationship between nonverbal behavior and deception intrigues people and represents big business. In this article, we will review what is currently known about this topic. We discuss theories about why liars and truth tellers would display different behaviors, and then review research on actual nonverbal cues to deception. As we will see, research consistently shows that attempting to read truth and deception results in 
very poor accuracy rates, most likely because the behavioral traces of deception are faint.

\section{Why would truth tellers and liars display different behaviors? Theories of nonverbal cues to deception}

There are many theories explaining the relationship between nonverbal behavior and deception. We will not offer an overview of past distinctions between these theoretical views, for such see Bond, Levine and Hartwig (2015). Instead, we will restructure the theoretical discussion and offer a reclassification of deception theories. Our rationale for this restructure is that the field of deception has grown significantly since many of the classic conceptualizations were launched (Zuckerman, DePaulo, \& Rosenthal, 1981), and that both social and cognitive psychology, on which deception theory is ultimately based, have undergone major theoretical developments (Fiske \& Taylor, 2013).

Figure 1 about here

\section{Mental Process Theories: Emotion and Cognition}

A cluster of theories about nonverbal behavior and deception deals with the mental processes that are involved in producing a deceptive statement. These mental process theories share the premise that the most fruitful approach to understand the overt behavior of a liar is to inspect the internal processes that occur when lies are told. A critical distinction within such theories is that some focus on emotional processes and others on cognitive processes.

\section{Emotional Theory}

Ekman and Friesen (1969) presented the first modern theoretical conceptualization of nonverbal behavior and deception. Drawing on psychoanalytic models of the unconscious and early Darwinian theories of emotion, they 
hypothesized that a failure to completely suppress emotions associated with deception - anxiety, fear or even delight at the prospect of successful deceit - could result in nonverbal cues (the so-called leakage hypothesis). Such leakage cues could appear in various nonverbal channels, such as the face, arm/hands and legs/feet.

Ekman's (1985/1992) theory about deceptive leakage has been highly influential in the popular media, even spawning a major network show (Lie to $\mathrm{Me}$ ) supposedly partly based on Ekman's life and work. However, Ekman's claims have been highly criticized in the scientific community (Bond, Levine, \& Hartwig, 2015; Lindquist, Wager, Kober, Bliss-Moreau, \& Barrett, 2012). The problem with Ekman's emotional theory is that it is lacking clear definitions of what emotions liars are supposed to feel, and when. Moreover, why would a truth teller in the same situation not experience the same emotions? To put it differently, the theory confounds emotion and deception (National Research Council, 2003). Partly in reaction to the problems of emotional theory, recent theories have focused on the cognitive processes underlying deception.

\section{Cognitive Theories}

The notion that liars and truth tellers would differ in cognitive processes dates back to Zuckerman, DePaulo and Rosenthal's (1981) seminal paper. In the last decade, cognitive theories of deception have come to dominate the conceptual landscape. These theories generally reject the utility of focusing on liars' emotions. Instead, they seek to understand how and when lying is more cognitively taxing than telling the truth and how such cognitive load might manifest itself in nonverbal behavior.

Cognitive Load Theory. Vrij and colleagues have built a substantial body of work around the notion that in interview settings lying may be more cognitively 
demanding than telling the truth, which subsequently can be exploited for the purpose of lie detection (Vrij, Fisher, \& Blank, 2017; Vrij, Fisher, Blank, Leal, \& Mann, 2016; Vrij, Fisher, Mann, \& Leal, 2008). They have suggested a number of reasons for differences in cognitive load between liars and truth tellers to occur (Vrij et al., 2008b). For example, it may be that formulating a lie is more difficult than drawing a truthful account from memory. For a lie to be believable, it has to contain sufficient details as to bear the characteristics of a self-experienced event. Still, offering details that sound plausible requires imagination and liars may lack such imagination. In addition, offering details may be risky if the target of the lie has information that contradicts the liar's claims (Nahari, Vrij, \& Fisher, 2014).

Furthermore, truth tellers appear to take their credibility for granted in ways that liars do not. For example, truth tellers often express the belief that if they simply tell the truth like it happened, their innocence will become apparent to their communication partner (Kassin, 2005; Strömwall, Hartwig, \& Granhag, 2006). If liars are more prone to believe that their credibility is in jeopardy, they ought to expend more effort to come across as believable. Finally, whereas activating the truth often happens automatically, activating a lie is more intentional and deliberate, and thus requires mental effort (Gilbert, 1991; Walczyk, Roper, Seemann, \& Humphrey, 2003). Although these are good reasons to believe that lying places a stronger burden on the cognitive resources than telling the truth, lying may not give rise to clear cues in itself - it seems that specific interview protocols are required for clear cues to emerge (Vrij, Fisher, \& Blank, 2017).

Strategic Models. Strategic models are another branch of cognitive theories of deception. These models view the psychology of deception as a kind of game that demands a number of strategic decisions from the liar. They partly draw on 
Hilgendorf and Irving's (1981) classic model of the psychology of suspects' decision making: People who have incriminating information to conceal are faced with strategic choices about what information to admit to, what information to conceal, and what information to deny. Other researchers have elaborated on this notion, primarily in relation to strategic interviewing techniques (Granhag \& Hartwig, 2008). The most important point is the model's emphasis on liars' psychology as driven by planning, strategizing and calculation. Research has shown that insight into liars' interview strategies facilitates lie detection as long as investigators use specific interview techniques aimed to exploit these strategies (e.g. Cognitive Credibility Assessment, [Vrij, Fisher, \& Blank, 2017]; Strategic Use of Evidence, Granhag \& Hartwig [2015]; and the Verifiability Approach, Nahari [2018]).

\section{Social Psychological Approaches: Interpersonal and Contextual Theories}

The social psychological approaches to understanding nonverbal behavior to deception share the view that deceptive (and truthful) behavior occurs in a social context, in alignment with Lewin's (1943) notion that behavior is a function of the person and the environment. Here, we will bring to focus three theories that are based on this idea.

\section{Interpersonal Deception Theory}

Interpersonal Deception Theory (IDT) states that deception is a dynamic interaction between senders and receivers of messages (Buller \& Burgoon, 1996). This may sound trivial, but prior to IDT research paradigms rarely reflected the interactive nature of deception. IDT further states that deception unfolds in time: Senders monitor the behavior of receivers, and vice versa, and they mutually adjust their behavior in accordance with the feedback they receive from each other. Plausible as this may seem, IDT has been criticized on the grounds that it is conceptually 
underdeveloped and that it fails to generate testable hypotheses (DePaulo, Ansfield \& Bell, 1996).

\section{Self-Presentational Theory}

Drawing on Goffman's (1959) classic work on social behavior in ordinary life, DePaulo (1992) proposed a theory of the psychology of deception. DePaulo argued that lying is not an extraordinary form of social behavior, qualitatively different from other forms of conduct. Following Goffman (1959), who pointed out that life is like a theatre and that people often behave as actors on a stage, DePaulo suggested that most social behavior is not raw but that people edit, groom and adjust how they come across to others to pursue a variety of social goals. Such editing may occur on both verbal and nonverbal levels.

In the self-presentational view of deception, liars and truth tellers share a common goal: to come across as truthful. To achieve this goal, both liars and truth tellers may engage in deliberate (and automatic) self-presentational efforts and may engage in similar forms of behaviors to create a credible impression (Feldman, Forrest, \& Happ, 2002; Weiss \& Feldman, 2006). This is a radical theory of deception, because it emphasizes the similarities between lying and truth telling rather than the characteristics unique to deception. However, DePaulo (1992) also points out that there is a critical difference between the two activities: Both liars and truth tellers make claims of honesty, but in contrast to truth tellers, liars know that their claims are illegitimate. This so-called deception discrepancy may give rise to cues to deception in that liars embrace their stories less, and experience a more pronounced sense of deliberateness.

\section{Moral Psychology Theory}


As a theoretical framework for their seminal meta-analysis on accuracy in lie judgments, Bond and DePaulo (2006) introduced a new view of deception that emphasized the moral psychological elements of lying and judging lies. They proposed the double-standard hypothesis, which suggests that people have two sets of moral standards regarding the acceptability of lies: When we imagine ourselves being the target of deception, lying is a moral offense. However, when we ourselves tell a lie, we trivialize the seriousness of our behavior and readily generate justifications. Recall Ekman's emotional theory that liars might experience guilt and shame. In Bond and DePaulo's view, this may be nothing more than a projection in that we think that we ought to experience such emotions. When lying, we may be morally more pragmatic. We tell a lie for a reason, and we justify it to maintain our selfconcept as decent human beings (see self-concept maintenance theory, Mazar, Amir, \& Ariely, 2008; and moral hypocrisy theory, Monin \& Merritt, 2012). This theory offers a new and promising way to think about the psychology of deception, although deception scholars need to explore it in more detail.

\section{Nonverbal cues to deception: The evidence}

DePaulo et al. (2003) published the most comprehensive meta-analysis of cues to deception to date. It included 116 studies, examining 158 cues of which 102 could be considered nonverbal (vocal or visual). Fifty cues were examined in at least six studies, and since they give the most compelling results (DePaulo et al., 2003), we focus on these. Significant findings emerged for 14 of the 50 cues, and they are listed in Table 1. The cues are ranked in terms of their effect sizes. Cohen (1977) suggested that effect sizes of $.20, .50$, and .80 should be interpreted as small, medium, and large effects, respectively. Table 1 shows that the effect sizes for these diagnostic cues are typically small. The largest effect size was found for verbal and vocal immediacy, $d=$ 
.55 and the lowest for facial pleasantness, $d=.12$. Nine of the 14 cues listed in Table 1 have a nonverbal element, and the average effect size for these nine cues is $d=.25$. Given that 35 of the 50 cues were (at least in part) nonverbal cues and that a large majority of them (26 out of 35 or $74 \%$ ) did not show any relationship with deception, we conclude that the relationship between nonverbal cues and deception is faint and unreliable (e.g., DePaulo \& Morris, 2004).

The results for the verbal cues are more promising than those for the nonverbal cues. Eight of the cues listed in Table 1 contain a verbal element and the average effect size for the eight cues is $d=.30$. Moreover, only a small majority of verbal cues (10 out of 18 or 55\%) was unrelated to deception. In addition, an increasing body of research has shown that verbal cues to deceit can be elicited or enhanced when specific interview styles and protocols are introduced (Granhag \& Hartwig, 2015; Hartwig, Granhag, \& Luke, 2014; Vrij, Fisher, \& Blank, 2017). Such research does not exist in the nonverbal cues to deception area, so it remains doubtful that specific interview protocols can elicit or enhance nonverbal cues to deceit.

DePaulo et al.'s (2003) work has been very influential. Nowadays, researchers mainly focus on verbal cues to deceit, largely ignoring nonverbal behaviors. DePaulo et al.'s thorough examination of nonverbal cues and their conclusion that those cues are mostly unrelated to deception and, at best, weakly related, has discouraged many researchers to examine nonverbal cues. This is at least what we have noticed, because lively debates about the merits of nonverbal lie detection do no longer take place at the scientific conferences we attend. Yet, nonverbal lie detection remains highly popular amongst practitioners and in the media, as discussed in the next section. 
The most popular lie detection tools used in legal contexts have in common that they claim that nonverbal behavior can offer guidance in the search for truth. In many ways, these practice-based techniques are similar in that they share the naïve psychological view that a deceitful person is one under emotional pressure, leaking cues to their internal distress through channels they are not aware of.

There are numerous books, manuals, and training seminars sold under the pretense that they will make the consumer better at distinguishing between lies and truths. We will not enumerate them all. However, it is worth discussing some of the most pervasive techniques, and comparing their claims to empirical reality.

\section{The Behavior Analysis Interview (BAI).}

The Behavior Analysis Interview (BAI) is part of the Reid school of interrogation, which has been widely criticized because of its link to miscarriages of justice (Garrett, 2015). It consists of a list of 15 questions (e.g. "Did you commit the crime?") to which truth tellers and liars are supposed to give different (non)verbal responses. The Reid interrogation manual (Inbau et al., 2013) refers to a field study as support for the BAI (Horvath et al., 1994). The problem of this field study, also acknowledge by Horvath et al. (1994), was a lack of ground truth because the researchers actually did not know which of the 60 suspects were telling the truth and which ones were lying. In the only laboratory experiment testing the BAI to date, the liars and truth tellers did not display the nonverbal responses predicted in the BAI (Vrij, Mann, \& Fisher, 2006).

\section{Facial micro-expressions.}

Ekman has long argued that deceptive emotional information is leaked by micro-expressions, fleeting but complete facial expressions that are thought to reveal the felt emotion during emotional concealment (Ekman, 1985). This idea has enjoyed 
popularity in the media (Henig, 2006) and scientific community (Schubert, 2006), despite a lack of research. Porter and ten Brinke (2008) conducted the first and to date only published experiment into the relationship between micro-expressions and deception. They found micro-expressions in only 14 video-fragments $(2 \%$ of the video-fragments included in the study), and six were displayed by truth tellers rather than by liars.

\section{Neurolinguistic programming (NLP).}

Neurolinguistic programming (NLP) is offered to practitioners as a tool to improve communication skills, including how to detect deception. In the NLP literature it is suggested that truth tellers and liars differ from each other in the specific eye movements they display. Interestingly, the founders of NLP (Bandler \& Grinder, 1979) never suggested this, but the claim has appeared elsewhere. For example, Rhoads and Solomon (1989) claimed a link between eye movements and deception, referring to four independent studies without referencing them. Scientific studies found no support for the NLP related eye movement hypothesis (Mann et al., 2012b; Wiseman et al., 2012).

\section{The baseline approach.}

Sometimes investigators are trained to examine a suspect's natural, truthful, nonverbal behavior at the beginning of an interview through small talk (Frank, Yarbrough, \& Ekman, 2006; Inbau et al., 2013). This behavior is then used as a baseline comparison with the investigative part of the interview, whereby any difference in response between the baseline and investigative part of the interview could be interpreted as a sign of deceit (Vrij, 2016). The problem with the approach is obvious: There are fundamental differences between small talk and the investigative part of the interview, which could influence someone's behavior, and this 'apple- 
orange' comparison will be prone to incorrect judgments (Moston \& Engelberg, 1993). Although baseline deception research exists (Brandt, Miller, \& Hocking, 1980a, b; Feeley, deTurck, \& Young, 1995), research comparing specific behaviors of truth tellers and liars during the baseline and investigative parts of the interview does not exist.

In conclusion, practitioners are offered a variety of lie detection techniques which amount to little more than pseudoscience. It is a lamentable state of affairs that professionals are taught all sorts of techniques with no evidence that they actually work. As discussed earlier, misjudging deception can have severe and costly consequences. Unfortunately it is not illegal to bring bogus training packages onto the market. Professionals should ask for conclusive evidence that the proposed techniques actually work, before signing up to any course in 'lie-detection'.

\section{How the cues relate to the theoretical perspectives?}

The extent to which the empirical landscape supports the theories we have outlined is difficult to determine, because some theories predict similar patterns, and some cues can be taken as support for several theories. This is perhaps a reflection of a problematic state of affairs theory-wise in that we have yet to arrive at a sufficiently coherent synthesis of principles to allow for unambiguous predictions and conclusions.

In some ways, it is easier to point to theories that have not received empirical support. From the pattern derived from meta-analyses, it is clear that the emotional theory is not supported much, with only two cues (nervousness and tense) being weakly related to deception. This is an important finding for the study of nonverbal behavior and deception, because the emotional theory makes the most definitive predictions about the existence of nonverbal signs of deception. 
Inspecting the patterns of strongest cues in Table 1, there are several things to note. First, the finding that cues to deception are generally weak supports both the self-presentational perspective and double-standard hypothesis. Second, when looking at the cues to deception that do appear to be diagnostic, the findings that liars sound less immediate and come across as more ambivalent further supports the selfpresentational perspective in that it shows that lies appear less embraced. However, these findings can also be considered support for the strategic models, which argue that lying involves calculation. It may be that the evasiveness, uncertainty, ambivalence and lack of details found in the meta-analytic patterns are not unintentional - as the self-presentational perspective might suggest - but may be the result of liars being more reluctant to commit to a firm statement because they are wary of the possibility of being disproven. Third, there is also support for the cognitive load perspective in that, compared to truth tellers, liars appear less immediate, more ambivalent, and more uncertain, and their statements are less detailed and sound less plausible. However, it should be noted that this is the strength of cues that arise without any provocation - recent research has shown that cues to cognitive load can become more pronounced through various interventions (Vrij et al., 2016; Vrij, Fisher, \& Blank, 2017).

In summary, the empirical evidence provides some support for the selfpresentational perspective and the cognitive load theory, and is also consistent with a strategic and morality based view. We believe that the scattered nature of the results patterns suggests that researchers might need to rethink the theoretical landscape to come to an overarching theory. As a starting point, it may be fruitful to design experiments that pit theories against each other in order to get a better understanding 
of why particular cues arise or do not arise and under which circumstances they may or may not arise.

\section{Reasons why not many diagnostic cues to deceit have been found to date}

In the previous section we discussed two important reason why not many cues to deceit have been found to date: Truth tellers and liars often have similar experiences (the self-presentational perspective) and liars often trivialize the seriousness of their behavior (the double-standard hypothesis). In this section we discuss further reasons. Some reasons make it more likely that more nonverbal cues to deception will emerge in future research, but other reasons make it unlikely that many more nonverbal cues ever will be found. We start with the optimistic reasons (reasons 1 to 4$)$.

\section{1) Some cues are overlooked}

Perhaps several of the more diagnostic cues to deception have not been examined yet to date. We give three examples. Different types of smiles exist but most deception researchers do not distinguish between them. Smiling emerges as a cue to deceit when subcategories are taken into account. Ekman (1985) has identified a number of different smiles, including a distinction between felt and false smiles. Felt smiles include smiles in which the person actually experiences a positive emotion, whereas false smiles are deliberately contrived to convince another person that a positive emotion is felt, when in fact it is not. Felt smiles are accompanied by the action of two muscles: the zygomatic major that pulls the lip corners upward toward the cheekbone and the orbicularis oculi that raises the cheek and gathers skin inward from around the eye socket. The latter change produces bagged skin below the eyes and crow's-feet creases beyond the eye corners. In false smiles, the action of the orbicularis oculi muscle causing the effects around the eye is often missing (Frank, 
Ekman, \& Friesen, 1993). Ekman and colleagues found that truth tellers displayed more felt smiles than did liars, whereas liars displayed more false smiles than did truth tellers. When the distinction between felt and false smiles was not made, truth tellers smiled as frequently as liars (Ekman, Friesen, \& O'Sullivan, 1988). Other differences include that false smiles are more asymmetrical, appear too early or too late, and often last longer (Ekman, Davidson, \& Friesen, 1990).

Non-verbal communication researchers (Efron, 1941; Ekman \& Friesen, 1972; McNeill, 1992) have identified many subcategories of hand gestures but deception researchers typically ignore these subcategories. Research has shown that cues to deceit may arise when subcategories are taken into account. When in an experiment hand gestures were taken as a whole no difference emerged between truth tellers and liars, but differences were found in subcategories of hand gestures (Caso, Maricchiolo, Bonaiuto, Vrij, \& Mann, 2006). Truth tellers made significantly more deictic gestures (pointing or using the hand to make reference to an object), whereas liars made significantly more metaphoric gestures (illustrations of an abstract concept such as a closed fist to indicate strength), which are typically made when describing abstract ideas (McNeill, 1992).

Gaze aversion (looking away from the conversation partner) is the strongest stereotypical belief of deception (Global Deception Team, 2006), but is actually not associated with deception (DePaulo et al., 2003). This research typically examines visual saccadic eye movements, which are eye movements that change the direction of people's visual attention. However, saccadic eye movements also occur when people are not inspecting a visual scene, and often without the person being aware of making such movements. These movements occur when people are engaged in tasks that require search through long-term memory. Truths, more than lies, are based on 
extensive and frequent interactions with the real world, and therefore more readily accessible from long-term memory (Ganis et al. 2003). It has been found that truth tellers displayed fewer non-visual saccades than liars (Vrij, Oliveira, Hammond, \& Ehrlichman, 2015).

\section{2) Unprecise measurements}

Another explanation for the lack of diagnostic nonverbal cues to deception is that nonverbal behaviors are typically measured too roughly in research (often as frequency per minute of videofootage) and/or are not linked with speech (Bull, 2009; Ekman, 1981). Although eye contact with a conversation partner does not discriminate truth tellers from liars when measured as average per minute of interview, it does when examined more subtly. It has been found that liars demonstrate slightly prolonged episodes of eye contact that appear somewhat unnaturally intense as if they wanted to 'check out' their conversation partner, a phenomenon labeled deliberate eye contact (Mann et al., 2012a, 2013a, b). There are two reasons why liars seek deliberate eye contact. First, they try to convince their conversation partner that they are telling the truth, and when people attempt to convince others, they tend to looking them in the eyes (Kleinke, 1986). Second, liars tend to monitor their conversation partner's reactions carefully to assess whether they appear to be getting away with their lie (Buller \& Burgoon, 1996).

Others pointed out that nonverbal behavior should be examined in relation to speech content (Bull, 2009; Ekman, 2001). It is hereby claimed that in particular mismatches between speech and behavior could be indicative of deceit (e.g. a head nod while answering "no"). Although such claims are typically illustrated with examples, there is no systematic research available supporting this claim.

\section{3) Idiosyncratic behavior}


Perhaps nonverbal cues to deceit occur on an individual level, that is, different individuals may give their lies away in different ways (DePaulo et al., 2003). Empirical studies present results at a group level rather than at an individual level and therefore such studies, as well as meta-analyses based on such studies, cannot capture signs of deceit at an individual level, because idiosyncratic cues do not become apparent. It is debatable how useful idiosyncratic cues are for practitioners who try to detect deceit. Idiosyncratic cues imply that each individual displays an almost unique set of cues to deceit, and this probably also varies with the type of lie told and situation. An investigator would have no idea which cues to rely on in any individual case.

\section{4) A cluster of cues may be more diagnostic}

It could be that when researchers examine each nonverbal cue individually, no diagnostic cue to deception occurs, but that a diagnostic pattern will arise when a combination of cues is taken into account (DePaulo \& Morris, 2004). This could perhaps explain why concepts such as immediacy, ambivalence, and uncertainty all emerged as diagnostic cues to deceit (see Table 1). Making assessments of such states is likely to be based on a cluster of behaviors rather than on individual cues.

\section{5) Situational differences}

It has been argued that cues to deceit are more likely to occur when the stakes are high rather than low (Ekman, 1985; Frank \& Svetieva, 2012; O’Sullivan, Frank, Hurley, \& Tiwana, 2009). In high-stakes situations, when the consequences of being judged as deceptive are serious, liars may feel stronger emotions, may experience more cognitive demand, and may be more motivated to manage their behavior to appear credible. In their meta-analysis, Hartwig and Bond (2014) examined the detectability of lies based on nonverbal cues and compared settings which elicit 
strong emotions with settings of a more trivial nature. No difference was found in the detectability of lies between these two settings. The same meta-analysis did not find an effect for motivation either. The reason for these null-effects is that emotion and motivation will also affect truth tellers. For example, liars may be more likely to display nervous behaviors when the stakes are high, but so are truth tellers (Bond \& Fahey, 1987; Ofshe \& Leo, 1997), which means that the difference between them will not change.

It is more likely that the situation will overshadow differences in behavior between truth tellers and liars. For example, being accused of wrongdoing may result in different reactions. Some people may panic, whereas other people do not, but instead put effort in trying to convince the accuser that they are innocent. Such differential reactions are likely to occur in both liars and truth tellers and could overshadow the typically subtle nonverbal differences between them. This may explain why in one experiment (Vrij, 1995), nonverbal cues to deceit emerged in an information-gathering type of interview (in which interviewees were asked to report in their own words their activities) but not in an accusatory type of interview (in which interviewees were accused of wrongdoing, see also Vrij et al., 2017b).

\section{6) Contagious behaviors}

People often automatically and unconsciously mimic the behavior of their interaction partners, as seeing someone behave in a particular way activates a behavioral representation, causing the perceiver to adopt the exhibited behavior (Chartrand \& Bargh, 1999). It is difficult to see how behavior can be indicative of deception if someone's behavior is, at least in part, influenced by the behavior of the conversation partner. In fact, it easily can go wrong. In one experiment, a (mock) police officer was fidgeting with his fingers when interviewing half of the innocent 
and guilty mock suspects (experimental condition), whereas he kept his fingers still in the other half of the interviews (control condition). Both innocent and guilty suspects moved their fingers more in the experimental condition. When observers saw the videotaped interviews, they perceived the innocent and guilty suspects in the experimental condition as more deceptive than those in the control condition (Akehurst \& Vrij, 1999). In other words, the suspects in the experimental condition unconsciously mimicked the fidgety behavior of the officer and their fidgety behavior made them appear suspicious.

The behavior of one person can also influence the behavior of another person in settings other than a mimicry setting. Investigators are sometimes advised to get closer physically to suspects during an interrogation (Inbau et al., 2013). Such behavior may well elicit gaze aversion in suspects as people typically start to avert their gaze when their personal space is invaded (Argyle \& Dean, 1965). Since investigators typically perceive gaze aversion as a sign of deceit, such a response could thus raise suspicion.

\section{7) Strategies employed by truth tellers and liars}

Liars employ strategies to appear convincing. They do this more frequently than truth tellers, who tend to believe that the truth is transparent (illusion of transparency, Gilovich, Savitsky, \& Medvec, 1998). The nonverbal strategies liars and truth tellers employ are likely to be the same: Both will try to suppress behaviors they think appear suspicious -mostly signs of nervousness- and will try to replace them with behaviors that they think will look honest (Hocking \& Leathers, 1980). It is a different story for speech content. Truth tellers' strategy is to 'tell it all' and to give as much detail as they can remember. In contrast, liars do not wish to give too much detail out of fear that investigators can check such details and will discover that they 
are lying (Hartwig, Granhag, \& Strömwall, 2007; Nahari, Vrij, \& Fisher, 2012). In summary, to appear convincing truth tellers and liar employ similar nonverbal strategies but different verbal strategies (Hartwig, Granhag, Strömwall, \& Doering, 2010; Vrij, Mann, Leal, \& Granhag, 2010). This may explain why speech content is more revealing about deception than nonverbal behavior.

\section{Accuracy in lie detection through observing nonverbal cues}

Bond and DePaulo (2006) published the most comprehensive meta-analysis about people's ability to detect deceit to date. They analyzed the results from 206 documents including almost 25,000 observers. These observers made veracity judgements based on watching videotapes, listening to audiotapes or reading transcripts from truth tellers and liars. On average, 54\% of their judgments were correct, a performance just better than chance (50\%). It made a difference to which medium observers were exposed. When they could only see the target person, they performed worse (52\% accuracy) than when they could only hear the target person $(63 \%)$, with an accuracy rate in between those two scores $(56 \%)$ when they could both see and hear the target person. This suggests that access to verbal content facilitates discrimination between truths and lies. A meta-analysis about the effect of lie detection training supported this conclusion: Training focusing on vocal and visual cues to deceit only resulted in small improvements, whereas training related to speech content resulted in medium sized improvements (Hauch, Sporer, Michael, \& Meissner, 2016). Of course, observers may make veracity judgements not to their full potential when observing behavior, and may fail to spot some diagnostic cues. Hartwig \& Bond (2014) addressed this issue by examining accuracy rates based on multiple nonverbal cues that were coded objectively. Although this is the 'ideal' 
situation for nonverbal lie detection, and includes complex decision making models that only computers can make, the accuracy rate was still rather low, $67.68 \%$.

Apart from lower accuracy, Bond and DePaulo's (2006) meta-analysis revealed a second negative consequence of paying attention to visual cues only: Messages judged from visual cues result in a lie bias - the tendency to judge someone as a liar. Access to visual information only should encourage the use of nonverbal stereotypes because, when speech content is unavailable, observers have little other than their stereotypical beliefs to rely on (Bond \& DePaulo, 2006). Since nonverbal stereotypes relate to the behavior of liars rather than truth tellers (e.g., liars lack eye contact and fidget), a lie bias is the result. This could perhaps explain why American police investigators typically show a lie bias (Kassin, Meissner, \& Norwick, 2005; Meissner \& Kassin, 2002), whereas their British counterparts do not (Mann, Vrij, \& Bull, 2004; Mann, Vrij, Fisher, \& Robinson, 2008). American officers are trained to pay attention to nonverbal behavior when attempting to detect deceit, whereas British investigators are instructed to ignore nonverbal behavior (e.g. Vrij et al., 2017b).

Following the same reasoning, using nonverbal lie detection tools could result in a lie bias. People find it difficult to pay attention to speech and behavior simultaneously (Patterson, 1995). Therefore, when investigators are taught to pay attention to behavior, they will be inclined to solely focus on behavior and to ignore speech content.

Bond and DePaulo (2006) also compared the performance of presumed deception experts (e.g. law enforcement personnel, psychiatrists, job interviewers) with laypersons (typically college students), but found no difference in accuracy between the two groups. A difference emerged between them in terms of confidence, with deception experts being more confident than laypersons (Kassin, Meissner, \& 
Norwick, 2005). The tendency to be confident is not unique to police officers or lie detection, but common amongst many groups of professionals in carrying out various tasks (Allwood \& Granhag, 1999).

Although the Bond and DePaulo (2006) article is more than ten years old, it is still the most comprehensive text about observers' ability to detect lies. Since then research has shown that under some circumstances people's ability to detect lies becomes substantially better, but no line of research has shown that such an improved accuracy rate can be obtained through observing behaviors. Instead, using specific interview protocols and analyse speech content offers improvements (Hartwig, Granhag, \& Luke, 2014; Vrij, Fisher, \& Blank, 2017), so does taking into account contextual factors, including familiarity with the topic and context of the conversation (Levine, 2015).

\section{People's views on the relationship between nonverbal behavior and deception}

Table 2 presents an overview of a selection of nonverbal cues to deceit, which are often claimed to be diagnostic cues to deceit on the internet, in popular magazines, non-scientific books or American police manuals (Vrij, 2008). For each cue Table 2 presents (1) its actual relationship with deception according to DePaulo et al.'s (2003) meta-analysis and (2) how people believe it is related to deception, based on numerous surveys in the area (Vrij, 2008).

Table 2 shows first that 13 of the 16 cues are not related to deception, and the three that are diagnostic show only small effect sizes. In contrast, people typically believe that most of these 16 cues are related to deception and the direction of these relationships (e.g., liars display gaze aversion and make many movements) is in accordance with what can be read on the internet, or in popular magazines, nonscientific books and police manuals about the topic. Deception experts and laypersons 
share the same stereotypical views about nonverbal cues to deceit (Vrij, Akehurst, \& Knight, 2006).

\section{Why people continue to make nonverbally based veracity assessments}

There are numerous reasons as to why people continue to make nonverbally based veracity assessments despite the lack of evidence that they actually work. In this section we present what we believe are the main reasons.

\section{Little choice other than to observe behaviors}

There are situations in which investigators have little choice other than to observe behaviors, for example, when attempting to spot wrongdoers in public spaces such as airports, public transport, and sporting events. Intriguingly, we are not aware of any published peer-reviewed research about what officers are supposed to look for in such situations. In general, we believe that the nonverbal deception research carried out to date does not fit well with situations in which such assessments are important, see Box 1. The (U.S.) Government Accountability Office (2017) reviewed the evidence behind the (U.S.) Transportation Security Administration (TSA) program of spotting possible wrongdoers at American airports. It concluded that the TSA has no evidence that most indicators it uses to identify wrongdoers at airports are actually suitable for that purpose.

Police interview styles differ between the U.S and Western European countries. In the U.S. accusatory interview techniques are typically employed, whereas in Western Europe information-gathering techniques are used (Meissner et al., 2014). Officers who use accusatory interview styles of interviewing are encouraged to pay attention to nonverbal behavior, whereas those who use information-gathering interviews are encouraged to solely concentrate on the speech content (Vrij et al., 2017b). This difference could be the result of how much a suspect 
speaks. Suspects are encouraged to speak more in information-gathering interviews and actually say more in such interviews- than in accusatory interviews (Meissner et al., 2014). The less suspects say (accusatory interviews), the more inclined investigators will be to pay attention to nonverbal behaviors (Vrij et al., 2017b).

\section{Lack of self-insight}

People do not have proper insight into their own behavior when they lie. In an experiment participants both told the truth and lied and were subsequently asked how they thought they behaved in both interviews (Vrij, Edward, \& Bull, 2001). They mistakenly believed that they showed stereotypical behaviors such as gaze aversion and excessive movements when they lied. When people lie they are more aware of their behavior than when they tell the truth, and are particularly aware of exhibiting any behaviors that they think look suspicious. Liars think that displaying gaze aversion and making movements looks suspicious, so they are aware of these behaviors each time they display them. What they do not realize is that they also display such behaviors when telling the truth.

\section{The power of stereotypes}

Social psychology research has shown that once stereotypical views have been formed (e.g., the notion that liars display gaze aversion and excessive movements), various cognitive processes are activated with the result that these stereotypical views are most likely to endure. For example, once incorrect views have been formed, people will perceive supporting evidence that in fact does not exist, so-called illusory correlations (Stroessner \& Plaks, 2001). To illustrate, when observers were informed that someone was lying, they overestimated the amount of gaze aversion the alleged liar actually displayed (Levine, Asada, \& Park, 2006).

Also, people tend to seek information that confirms rather than disconfirms their 
beliefs (so-called confirmation bias, Darley \& Gross, 1983). Any support they find for their beliefs will boost their confidence that their views are correct, making it less likely that they will alter them. Of course, people will always find supporting evidence, for example, sometimes liars will look away or will make excessive movements.

Moreover, when people come across an example that disconfirms their beliefs, they are more likely to disregard it than interpret this new evidence as a sign that their initial belief is incorrect, a phenomenon called belief perseverance (Anderson, Lepper, \& Ross, 1980).

Also, once people have formed an opinion that makes sense to them, they will come up with further reasons to support their view (the power of thinking, Tesser, 1978). If people are asked why they think liars look away, they may think of reasons to corroborate this view and search their memory for examples where they encountered liars who averted their gaze (Strömwall, Granhag, \& Hartwig, 2004). Thinking about examples that support their beliefs will strengthen their opinion.

Finally, people often do not receive adequate feedback that is required to learn from their own experience and to discover that their views are inaccurate. For feedback to be effective, it needs to be given frequently, reliably and immediately. In terms of feedback about nonverbal cues to deception, observers should be informed immediately after every interaction with another person whether that person was lying or not. Of course, this is not a realistic scenario. If people discover that they have been lied to, it is often a long time after the interaction took place (Park, Levine, McCornack, Morrison, \& Ferrara, 2002), by which time they have probably forgotten how the person behaved.

Insert Box 1 about here

\section{Culturally transmitted misbeliefs}


It is likely that most misbeliefs about nonverbal behaviour and deception are culturally transmitted (Sperber, 2009). For example, there are numerous popular writings about the relationship between nonverbal behavior and deception. Most of them reiterate common stereotypes and boldly state nonverbal lie detection works. Therefore, most people will have been exposed to incorrect information about the topic (Hurley, Griffin, \& Stefanone, 2014), believing it to be true.

\section{Future directions in nonverbal deception research}

One aim of this review was to reveal gaps in nonverbal deception research, of which we have identified three. First, more work is needed on the theoretical side, including carrying out experiments that pit existing theories against each other, so that their strengths and weaknesses can be revealed. Such experiments should also aim to search for an overarching theory that explains the complicated findings in this domain better than the existing theories. Second, we presented several reasons as to why not many diagnostic cues to deceit have been found to date. Several of them presented an optimistic view that more diagnostic cues could be found and these positive reasons are worth to explore further. Third, researchers should focus on examining nonverbal behaviors in settings where there is no alternative to making nonverbal veracity assessments. Although this advice sounds obvious, it has not been followed to date.

\section{Concluding remarks}

If we take a bird's-eye view of the nonverbal communication and lie detection world we see, first of all, a broken theoretical landscape. Many theories do exist, but none of them appears to fully capture the relationship between nonverbal behavior and deception. Amongst the inhabitants in this landscape, we find liars who tell their stories in various settings, including in settings where nonverbal communication is crucial. Those liars are (surprisingly) ignored, and the research focus is on liars who 
act in settings where nonverbal communication is less important. We also find liecatchers who are not as good at reading other people as they may think. In fact, their skills are mediocre and they hold robust misbeliefs about nonverbal cues to deceit. They also appear active in telling each other that their method of lie detection works without providing the crucial evidence to support these claims.

\section{Summary points}

1) Various theories about nonverbal communication and deception exists but they do not fully explain why liars behave the way they behave.

2) Nonverbal cues to deception are faint and unreliable, but verbal cues to deceit are more diagnostic

3) A more optimistic picture about nonverbal cues to deception may emerge if researchers examine the cues differently and do so in more relevant settings

4) People's ability to detect lies is mediocre, particularly if they only have access to visual cues

5) People overestimate the relationship between nonverbal behavior and deception and assume many relationships that are actually untrue (stereotypes).

6) These stereotypical views are hard to debunk

\section{Acknowledgement}

The time Aldert Vrij spent working on this article was funded by the Centre for Research and Evidence on Security Threats (ESRC Award: ES/N009614/1) 


\section{References}

Akehurst, L., \& Vrij, A. (1999). Creating suspects in police interviews. Journal of Applied Social Psychology, 29, 192-210. Doi: 10.1111/j.1559- 1816.1999.tb01381.x

Allwood, C. M. \& Granhag, P. A. (1999). Feelings of confidence and the realism of confidence judgments in everyday life. in P. Juslin \& H. Montgomery (Eds.), Judgment and decision making: Neo-Brunswikian and process-tracing approaches (pp. 123-146). Mahwah NJ: Lawrence Erlbaum.

Anderson, C. A., Lepper, M. R., \& Ross, L. (1980). Perseverance of social theories: The role of explanation in the persistence of discredited information. Journal of Personality and Social Psychology, 39, 1037-1049. Doi: 10.1037/h0077720

Argyle, M., \& Dean, J. (1965). Eye-Contact, Distance and Affiliation. Sociometry, 28, 289304. Doi: $10.2307 / 2786027$

Bandler, R. \& J. Grinder (1979). Frogs into princes. Moab, UT: Real People Press.

Bond, C. F., \& DePaulo, B. M. (2006). Accuracy of deception judgments. Personality and Social Psychology Review, 10, 214-234. Doi: 10.1207/s15327957pspr1003_2

Bond, C. F., \& Fahey, W. E. (1987). False suspicion and the misperception of deceit. British Journal of Social Psychology, 26, 41-46. DOI: 10.1111/j.2044-8309.1987.tb00759.x

Bond, C. F., Jr., Levine, T. R., \& Hartwig, M. (2015). New findings in nonverbal lie detection. In P. A. Granhag, A. Vrij, \& B. Verschuere (Eds.), Deception detection: Current challenges and new directions (pp. 37-58). Chichester: Wiley.

Brandt, D. R., Miller, G. R., \& Hocking, J. E. (1980a). The truth-deception attribution: Effects of familiarity on the ability of observers to detect deception. Human Communication Research, 6, 99-110. Doi: 10.1111/j.1468-2958.1980.tb00130.x/full 
Brandt, D. R., Miller, G. R., \& Hocking, J. E. (1980b). Effects of self-monitoring and familiarity on decepion detection. Communication Quarterly, 28, 3-10. doi:10.1080/01463378009369370

Bull, P. (2009). Detecting deceit: current issues. In T. Williamson, B. Milne, \& S. P. Savage (Eds.), International Developments in Investigative Interviewing (pp. 190-206). Devon: Willan Publishing.

Buller, D. B., \& Burgoon, J. K. (1996). Interpersonal deception theory. Communication Theory, 6, 203-242. Doi: 10.1111/j.14682885.1996.tb00127.x.

Caso, L., Maricchiolo, F., Bonaiuto, M., Vrij, A., \& Mann, S. (2006). The impact of deception and suspicion on different hand movements. Journal of Nonverbal Behavior, 30, 1-19. Doi: 10.1007/s10919-005-0001-z

Chartrand, T. L., \& Bargh, J. A. (1999). The chameleon effect: The perception-behavior link and social interaction. Journal of Personality and Social Psychology, 76, 893-910. Doi: $10.1037 / / 0022-3514.76 .6 .893$

Cohen, J. (1977). Statistical power analysis for the behavioral sciences. New York: Academic Press.

Darley, J. M., \& Gross, P. H. (1983). A hypothesis-confirming bias in labelling effects. Journal of Personality and Social Psychology, 44, 20-33. Doi: 10.1037/0022-3514.44.1.20

DePaulo, B. M. (1992). Nonverbal behavior and self-presentation. Psychological Bulletin, 111, 203. doi:10.1037/0033-2909.111.2.203

DePaulo, B. M., Ansfield, M. E., \& Bell, K. L. (1996). Theories about deception and paradigms for studying it. Communication Theory, 6, 297-310.

DePaulo, B. M., Lindsay, J. L., Malone, B. E., Muhlenbruck, L., Charlton, K., \& Cooper, H. (2003). Cues to deception. Psychological Bulletin, 129, 74-118. Doi: 10.1037/00332909.129.1.74 
DePaulo, B. M., \& Morris, W. L. (2004). Discerning lies from truths: Behavioural cues to deception and the indirect pathway of intuition. In P. A. Granhag \& L. A. Strömwall (Eds.), Deception detection in forensic contexts (pp. 15-40). Cambridge, England: Cambridge University Press.

Efron, D. (1941). Gesture and environment. New York: King's Crown.

Ekman, P. (1981). Mistakes when deceiving. Annals of the New York Academy of Sciences, 364, 269-278.

Ekman, P. (1985). Telling lies: Clues to deceit in the marketplace, politics and marriage. New York: W. W. Norton. (Reprinted in 1992, 2001 and 2009).

Ekman, P., Davidson, R. J., \& Friesen, W. V. (1990). The Duchenne smile: Emotional expression and brain physiology II. Journal of Personality and Social Psychology, 58, 342-353. Doi: 10.1037/0022-3514.58.2.342

Ekman, P., \& Friesen, W. V. (1969). Nonverbal leakage and clues to deception. Psychiatry, 32, 88-106. Doi: 10.1080/00332747.1969.11023575

Ekman, P., \& Friesen, W. V. (1972). Hand movements. Journal of Communication, 22, 353374. Doi: 10.1111/j.1460-2466.1972.tb00163.x

Ekman, P., Friesen, W. V., \& O’Sullivan, M. (1988). Smiles when lying. Journal of Personality and Social Psychology, 54, 414-420. Doi: 10.1037/ 0022-3514.54.3.414

Epley, N. (2014): Mindwise: Why we misunderstand what others think, believe, feel, and want. New York: Alfred A. Knopf.

Feeley, T. H., deTurck, M. A., \& Young, M. J. (1995). Baseline familiarity in lie detection. Communication Research Reports, 12, 160-169.

Feldman, R. S., Forrest, J. A., \& Happ, B. R. (2002) Self- Presentation and Verbal Deception: Do Self-Presenters Lie More? Basic and Applied Social Psychology, 24, 163-170. Doi: 10.1207/S S15324834BASP2402_8 
Fiske, S. T., \& Taylor, S. E. (2013). Social cognition: From brains to culture. Sage.

Frank, M. G., \& Ekman, P., \& Friesen, W. V. (1993). Behavioral markers and recognizability of the smile of enjoyment. Journal of Personality and Social Psychology, 64, 83-93. Doi: $10.1037 / 0022-3514.64 .1 .83$

Frank, M. G., \& Svetieva, E. (2012). Lies worth catching involve both emotion and cognition: Commentary of Vrij and Granhag (2012). Journal of Applied Research in Memory and Cognition, 1, 131-133. Doi: 10.1016/j.jarmac.2012.04.006

Frank, M. G., Yarbrough, J. D., \& Ekman, P. (2006). Investigative interviewing and the detection of deception. In T. Williamson (Ed.), Investigative interviewing: Rights, research and regulation (pp. 229-255). Cullompton, Devon: Willan Publishing.

Freud, S. (1959). Collected papers. New York: Basic Books.

Ganis, G., Kosslyn, S. M., Stose, S., Thompson, W. L., \& Yurgelun-Todd, D. A. (2003). Neural correlates of different types of deception: An fMRI investigation. Cerebral Cortex, 13, 830-836. 10.1093/cercor/13.8.830

Garrett, B. L. (2011). Convicting the innocent: Where criminal prosecutions go wrong. Cambridge, MA, US: Harvard University Press. doi:10.4159/harvard.9780674060982

Gilbert, D. T. (1991). How mental systems believe. American Psychologist, 46, 107-119. doi:10.1037/0003-066X.46.2. 107

Gilovich, T., Savitsky, K., \& Medvec, V. H. (1998). The illusion of transparency: Biased assessments of others' ability to read one's emotional states. Journal of Personality and Social Psychology, 75, 332-346. Doi: 10.1037/0022-3514.75.2.332

The Global Deception Team (2006). A world of lies. Journal of Cross-Cultural Psychology, 37, 60-74. doi: 10.1177/0022022105282295 
Goffman, E. (1959). The presentation of self in everyday life (1 edition). New York, NY: Anchor.

Government Accountability Office (2017). Aviation Security: TSA does not have valid evidence supporting most of the revised behavioral indicators used in its behavior detection activities. www.gao.gov/assets/690/686001.pdf

Granhag, P.A. \& Hartwig, M. (2008). A new theoretical perspective on deception detection: On the psychology of instrumental mind-reading. Psychology, Crime \& Law, 14, 189-200. DOI: $10.1080 / 10683160701645181$

Granhag, P. A., \& Hartwig, M. (2015). The Strategic Use of Evidence (SUE) technique: A conceptual overview. In P. A. Granhag, A. Vrij, \& B. Verschuere (Eds.), Deception detection: Current challenges and new approaches (pp. 231-251). Chichester, England: Wiley.

Hartwig, M., \& Bond, C. F. (2014). Lie detection from multiple cues: A meta-analysis. Applied Cognitive Psychology, 28, 661-667. Doi: 10.1002/acp.3052.

Hartwig, M., Granhag, P. A., \& Luke, T. (2014). Strategic use of evidence during investigative interviews: The state of the science. In: Raskin, D.C., Honts, C.R., Kircher, J.C. (Eds.), Credibility Assessment: Scientific Research and Applications (pp. 1-36). Oxford, UK: Academic Press.

Hartwig, M., Granhag, P. A., \& Strömwall, L. (2007). Guilty and innocent suspects' strategies during police interrogations. Psychology, Crime, \& Law, 13, 213-227. DOI: $10.1080 / 10683160600750264$

Hartwig, M., Granhag, P. A., Strömwall, L, \& Doering, N. (2010). Impression and information management: On the strategic self-regulation of innocent and guilty suspects. The Open Criminology Journal, 3, 10-16. Doi: 10.2174/ 1874917801003020010 
Hauch, V., Sporer, S. L., Michael, S. W., \& Meissner, C. A. (2016). Does training improve the detection of deception? A meta-analysis. Communication Research, 43, 283-343. Doi: $10.1177 / 0093650214534974$

Henig, R. M. (February 5, 2006). Looking for the lie. New York Times. Retrieved July 12, 2007, from www.nytimes.com.

Hilgendorf, E. L., \& Irving, B. (1981). A decision-making model of confessions. In Psychology in Legal Contexts (pp. 67-84). Palgrave Macmillan, London. Doi: 10.1007/978-1-349-04917-2_5

Hocking, J. E., \& Leathers, D. G. (1980). Nonverbal indicators of deception: A new theoretical perspective. Communication Monographs, 47, 119-131. Doi: /10.1080/ 03637758009376025.

Horvath, F., Blair, J. P., \& Buckley, J. P. (2008). The Behavioral Analysis Interview: Clarifying the practice, theory and understanding of its use and effectiveness. International Journal of Police Science and Management, 10, 101-118.

Horvath, F., Jayne, B., \& Buckley, J. (1994). Differentiation of truthful and deceptive criminal suspects in behavioral analysis interviews. Journal of Forensic Sciences, 39, 793-807.

Houston, P., Floyd, M., \& Carnicero, S. (2012). Spy the lie. St. Martin's Press, New York.

Hurley, C. M., Griffin, D. J., Stefanone, M. A. (2014). Who told you that? Uncovering the source of believed cues to deception. International Journal of Psychological Studies, 6, 19-32. doi:10.5539/ijps.v6n1p19

Hyman, R. (1989). The psychology of deception. Annual Review of Psychology, 40, 133-154. Doi: 10.1146/annurev.ps. 40.020189.001025 
Inbau, F. E., Reid, J. E., Buckley, J. P., \& Jayne, B. C. (2013). Criminal interrogation and confessions, $5^{\text {th }}$ edition. Burlington, MA: Jones \& Bartlett Learning.

Kassin, S. M. (2005). On the psychology of confessions: Does innocence put innocents at risk? American Psychologist, 60, 215-228. doi:10.1037/0003-066X.60.3.215

Kassin, S. M., Meissner, C. A., \& Norwick, R. J. (2005). "I'd know a false confession if I saw one": A comparative study of college students and police investigators. Law and Human Behavior, 29, 211-227. Doi: 10.1007/s10979- 005-2416-9

Kleinke, C. L. (1986). Gaze and eye contact: A research review. Psychological Bulletin, 100, 78-100. Doi: 10.1037/0033-2909.100.1.78

Levine, T. R. (2015). New and improved accuracy findings in deception detection. Current Opinion in Psychology, 6, 1-5. Doi: 10.1016/j.copsyc.2015.03.003

Levine, T. R., Asada, K. J. K., \& Park, H. S. (2006). The lying chicken and the gaze avoidant egg: Eye contact, deception and causal order. Southern Journal of Communication, 4, 401-411. doi.10.1080/10417940601000576

Lewin, K. (1943). Defining the "Field at a Given Time." Psychological Review, 50, 292-310. Doi: $10.1037 / \mathrm{h} 0062738$

Lindquist, K. A., Wager, T. D., Kober, H., Bliss-Moreau, E., \& Barrett, L. F. (2012). The brain basis of emotion: A meta-analytic review. Behavioral and Brain Sciences, 35, 121-143. Doi: 10.1017/S0140525X11000446

Mann, S., Vrij, A., \& Bull, R. (2004). Detecting true lies: Police officers' ability to detect deceit. Journal of Applied Psychology, 89, 137-149. Doi: 10.1037/0021-9010.89.1.137

Mann, S., Vrij, A., Fisher, R. \& Robinson, M. (2008). See no lies, hear no lies: Differences in discrimination accuracy and response bias when watching or listening to police suspect interviews. Applied Cognitive Psychology, 22, 1062-1071.

Doi: 10.1002/acp.1406 
Mann, S., Ewens, S., Shaw, D., Vrij, A., Leal, S., \& Hillman, J. (2013a). Lying eyes: Why liars seek deliberate eye contact. Psychiatry, Psychology, and Law, 20, 452-461.

Mann, S., Vrij, A., Leal, S., Granhag, P. A., Warmelink, L., \& Forrester, D. (2012). Windows to the soul? Deliberate eye contact as a cue to deceit. Journal of Nonverbal Behavior, 36, 205-215. Doi: 10.1007/s10919-012-0132-y

Mann, S., Vrij, A., Shaw, D., Leal, S., Ewens, S., Hillman, J., Granhag, P. A., \& Fisher, R. P. (2013b). Two heads are better than one? How to effectively use two interviewers to elicit cues to deception. Legal and Criminological Psychology, 18, 324-340. Doi $10.1111 / \mathrm{j} .2044-8333.2012 .02055 . \mathrm{x}$

Mann, S., Vrij, A., Nasholm, E., Warmelink, L., Leal, S., \& Forrester, D. (2012). The direction of deception: Neuro-Linguistic Programming as a lie detection tool. Journal of Police and Criminal Psychology, 27, 160-166. Doi: 10.1007/s11896-011-9097-8.

Masip, J., Herrero, C., Garrido, E., \& Barba, A. (2011). Is the behaviour analysis interview just common sense?. Applied Cognitive Psychology, 25(4), 593-604. doi:10.1002/acp.1728

Mazar, N., Amir, O., \& Ariely, D. (2008). The dishonesty of honest people: A theory of selfconcept maintenance. Journal Of Marketing Research, 45, 633-644. doi:10.1509/jmkr.45.6.633

McNeill, D. (1992). Hand and Mind: What Gestures reveal about Thought. Chicago: The University of Chicago Press.

Meissner, C. A., \& Kassin, S. M. (2002). "He's guilty!": Investigator bias in judgments of truth and deception. Law and Human Behavior, 26, 469-480. Doi: 10.1023/A:1020278620751

Meissner, C. A., Redlich, A. D., Michael, S. W., Evans, J. R., Camiletti, C. R., Bhatt, S., \& Brandon, S. (2014). Accusatorial and information-gathering interrogation methods 
and their effects on true and false confessions: A meta-analytic review. Journal of Experimental Criminology, 10, 459-486. DOI: 10.1007/s11292-014-9207-6

Meyer, P. (2010). Lie spotting: Proven techniques to detect deception. St. Martin's Press, New York.

Monin, B., \& Merritt, A. (2012). Moral hypocrisy, moral inconsistency, and the struggle for moral integrity. In M. Mikulincer, P. R. Shaver, M. Mikulincer, P. R. Shaver (Eds.), The social psychology of morality: Exploring the causes of good and evil (pp. 167-184).

Washington, DC, US: American Psychological Association. doi:10.1037/13091-009

Moston, S. J., \& Engelberg, T. (1993). Police questioning techniques in tape recorded interviews with criminal suspects. Policing and Society, 6, 61-75.

Doi:10.1080/10439463.1993.9964670

Münsterberg, H. (1908). On the witness stand: Essays on psychology and crime. New York: Doubleday.

Nahari, G. (2018). The applicability of the verifiability approach to the Real world. In P. Rosenfeld (Ed.). Detecting Concealed Information and Deception: Verbal, Behavioral, and Biological Methods. Amsterdam: Elsevier

Nahari, G., Vrij, A., \& Fisher, R. P. (2012). Does the truth come out in the writing? SCAN as a lie detection tool. Law \& Human Behavior, 36, 68-76. DOI: 10.1007/s10979-0119264-6

Nahari, G., Vrij, A., \& Fisher, R. P. (2014). Exploiting liars' verbal strategies by examining the verifiability of details. Legal and Criminological Psychology, 19, 227-239, DOI:10.1111/j.2044-8333.2012.02069.x

National Research Council (2003). The polygraph and lie detection. Committee to Review the Scientific Evidence on the Polygraph. Washington, DC: The National Academic Press. 
Ofshe, R. J., \& Leo, R. A. (1997). The decision to confess falsely: Rational choice and irrational action. Denver University Law Review, 74, 979-1112.

O’Sullivan, M., \& Ekman, P. (2004). The wizards of deception detection. In P. A. Granhag \& L. A. Strömwall (Eds.), Deception detection in forensic contexts (pp. 269-286). Cambridge, England: Cambridge University Press.

O’Sullivan, M., Frank, M. G., Hurley, C. M., \& Tiwana, J. (2009). Police lie detection accuracy: The effect of lie scenario. Law and Human Behavior, 33, 542-543. Doi: 10.1007/s10979-009-9191-y

Park, H. S., Levine, T. R., McCornack, S. A., Morrisson, K., \& Ferrara, M. (2002). How people really detect lies. Communication Monographs, 69, 144-157. doi:10.1080/714041710

Patterson, M. L. (1995). Invited article: A parallel process model of nonverbal communication. Journal of Nonverbal Behavior, 19, 3-29. Doi: 10.1007/BF02173410

Pease, A., \& Pease, B. (2004). The definitive book of body language. New York: Bantam Dell. Pennebaker, J. W., Mehl, M. R., \& Niederhoffer, K. G. (2003). Psychological aspects of natural language use.: Our words, our selves. Annual Review of Psychology, 54, 547577 Doi: 10.1146/annurev.psych.54.101601.145041

Porter, S., \& ten Brinke, L. (2008). Reading between the lies: Identifying concealed and falsified emotions in universal facial expressions. Psychological Science, 19, 508-514. Doi: 10.1111/j.1467-9280.2008.02116.x.

Reid, J. E. \& Associates. https://reid.com/

Rhoads, S. A., \& Solomon, R. (1987). Subconscious rapport building: Another approach to interviewing. The Police Chief, 4, 39-41.

Scheck, B., Neufeld, P., \& Dwyer, J. (2003). Actual innocence: When justice goes wrong and how to make it right (Reprint edition). New York: Berkley. 
Schubert, S. (October, 2006). A Look Tells All. Scientific American Mind. Retrieved June 20, 2007 from www.sciamind.com.

Sperber, D. (2009). Culturally transmitted misbeliefs. Behavioral and Brain Sciences, 32, 534535. Doi:10.1017/S0140525X09991348

Sporer, S. L., \& Schwandt, B. (2006). Paraverbal indicators of deception: A meta-analytic synthesis. Applied Cognitive Psychology, 20, 421-446. Doi: 10.1002/acp.1190

Stroessner, S. J., \& Plaks, J. E. (2001). Illusory correlation and stereotype formation: Tracing the arc of research over a quarter century. In G. B. Moskowitz (Ed.), Cognitive social psychology: The Princeton symposium on the legacy and failure of social cognition (pp. 247-259). Mahwah, NJ: Erlbaum.

Strömwall, L. A., Granhag, P. A., \& Hartwig, M. (2004). Practitioners' beliefs about deception. In P. A. Granhag \& L. A. Strömwall (Eds.), Deception detection in forensic contexts (pp. 229-250). Cambridge, England: Cambridge University Press.

Strömwall, L. A., Hartwig, M., \& Granhag, P. A. (2006). To act truthfully: Nonverbal behaviour and strategies during a police interrogation. Psychology, Crime \& Law, 12, 207-219. doi:10.1080/10683160512331331328

Tesser, A. (1978). Self-generated attitude change. In L. Berkowitz (Ed.), Advances in experimental social psychology (volume 11, pp. 288-338). New York: Academic Press.

Trovillo, P. V. (1939a). A history of lie detection, I. Journal of Criminal Law and Criminology, $29,848-881$.

Trovillo, P. V. (1939b). A history of lie detection, II. Journal of Criminal Law and Criminology, 30, 104-119. 
Vrij, A. (1995). Behavioral correlates of deception in a simulated police interview. Journal of Psychology: Interdisciplinary and Applied, 129, 15-29.

DOI:10.1080/00223980.1995.9914944

Vrij, A. (2008). Detecting lies and deceit: Pitfalls and opportunities, second edition. Chichester: John Wiley and Sons.

Vrij, A. (2016). Baselining as a lie detection method. Applied Cognitive Psychology, 30, 1112-1119. Doi: 10.1002/acp.3288

Vrij, A., Akehurst, L., \& Knight, S. (2006). Police officers', social workers', teachers' and the general public's beliefs about deception in children, adolescents and adults. Legal and Criminological Psychology, 11, 297-312. Doi: 10.1348/135532505X60816

Vrij, A., Edward, K., \& Bull, R. (2001). People's insight into their own behaviour and speech content while lying. British Journal of Psychology, 92, 373-389.

DOI: $10.1348 / 000712601162248$

Vrij, A., Fisher, R., Blank, H. (2017a). A cognitive approach to lie detection: A metaanalysis. Legal and Criminological Psychology, 22, 1-21. Doi:10.1111/lcrp.12088

Vrij, A., Fisher, R., Blank, H., Leal, S., \& Mann, S., (2016). A cognitive approach to elicit nonverbal ane verbal cues of deceit. In J. W. van Prooijen \& P. A. M. van Lange (Eds.), Cheating, corruption, and concealment: The roots of dishonest behavior (pp. 284-310). Cambridge, England: Cambridge University Press.

Vrij, A., Fisher, R., Mann, S., \& Leal, S. (2008a). A cognitive load approach to lie detection. Journal of Investigative Psychology and Offender Profiling, 5, 39-43. doi:10.1002/jip.82

Vrij, A., \& Granhag, P. A. (2007). Interviewing to detect deception. In S. A. Christianson (Ed.), Offenders' memories of violent crimes (pp. 279-304). Chichester, England: John Wiley \& Sons, Ltd. 
Vrij, A., \& Granhag, P. A. (2012). Eliciting cues to deception and truth: What matters are the questions asked. Journal of Applied Research in Memory and Cognition, 1, 110-117. doi:10.1016/j.jarmac.2012.02.004

Vrij, A., Mann, S., \& Fisher, R. (2006). An empirical test of the Behaviour Analysis Interview. Law and Human Behavior, 30, 329-345. Doi: 10.1007/s10979-006- 9014-3

Vrij, A., Mann, S., Fisher, R., Leal, S., Milne, B., \& Bull, R. (2008b). Increasing cognitive load to facilitate lie detection: The benefit of recalling an event in reverse order. Law and Human Behavior, 32, 253-265. DOI 10.1007/s10979-007-9103-y.

Vrij, A., Mann, S., Leal, S., \& Granhag, P. A. (2010). Getting into the minds of pairs of liars and truth tellers: An examination of their strategies. The Open Criminology Journal, 3, 17-22. Doi: 10.2174/1874917801003010017

Vrij, A., Meissner, C. A, Fisher, R. P., Kassin, S. M., Morgan III, A., \& Kleinman, S. (2017b). Psychological perspectives on interrogation. Perspectives on Psychological Science. doi: 10.1177/ 1745691617706515

Vrij, A., Oliveira, J., Hammond, A., \& Ehrlichman, H. (2015). Spontaneous saccadic eye movement rate as a cue to deceit. Journal of Applied Research in Memory and Cognition, 4, 15-19. Doi: 10.1016/j.jarmac.2014.07.005

Vrij, A., \& Turgeon, J. (2018). Evaluating credibility of witnesses: Are we instructing jurors on invalid factors? Weiner Law School.

Walczyk, J. J., Roper, K. S., Seemann, E., \& Humphrey, A. M. (2003). Cognitive mechanisms underlying lying to questions: Response time as a cue to deception. Applied Cognitive Psychology, 17, 755-774. Doi:10.1002/acp.914

Weiss, B., \& Feldman, R. S. (2006). Looking good and lying to do it: Deception as an impression management strategy in job interviews. Journal of Applied Social Psychology, 36, 1070-1086. Doi: 10.1111/j.0021-9029.2006.00055.x 
Wiseman, R., Hatfield, H.R.T., Watt, C., ten Brinke, L., Porter, S., Couper, S-L., \& Rankin, C. (2012). The eyes don't have it: Lie detection and neuro-linguistic programming. PLoS ONE, 7, ArtIDe40259. Doi: 10.1371/journal.pone.0040259

Zuckerman, M., DePaulo, B. M., \& Rosenthal, R. (1981). Verbal and nonverbal communication of deception. In L. Berkowitz (Ed.), Advances in experimental social psychology (vol. 14, pp. 1-57). New York: Academic Press. 
Table 1. Diagnostic (non)verbal cues to deceit based on at least six measurements

\begin{tabular}{|l|l|l|}
\hline \multicolumn{1}{|c|}{ Cue } & d-score & Type of cue \\
\hline $\begin{array}{l}\text { Verbal and vocal immediacy (impressions) (Responses that sound } \\
\text { direct, relevant, clear and personal) }\end{array}$ & -0.55 & Verbal and vocal \\
\hline $\begin{array}{l}\text { Discrepant, ambivalent (Communication seems internally inconsistent } \\
\text { or information from different sources (e.g. face vs voice) seems } \\
\text { contradictory; speaker seems to be ambivalent) }\end{array}$ & 0.34 & $\begin{array}{l}\text { Mixture of } \\
\text { verbal, vocal and } \\
\text { visual }\end{array}$ \\
\hline Details (units of information) & -0.30 & Verbal \\
\hline $\begin{array}{l}\text { Verbal and vocal uncertainty (impressions) (Speaker seems } \\
\text { uncertain, insecure or not very dominant, assertive or empathic; speaker } \\
\text { seems to have difficulty in answering the question) }\end{array}$ & 0.30 & Verbal \\
\hline $\begin{array}{l}\text { Nervous, tense (overall) (Speaker seems nervous or makes body } \\
\text { movements that seem nervous) }\end{array}$ & 0.27 & Visual \\
\hline Vocal tension (Voice sounds tense, not relaxed) & 0.26 & Vocal \\
\hline Logical structure (Consistency and coherence of statements) & -0.25 & Verbal \\
\hline Plausibility (Degree to which the message seems likely or believable) & -0.23 & Verbal \\
\hline $\begin{array}{l}\text { Frequency, pitch (Voice pitch sounds high or fundamental frequency of } \\
\text { the voice) }\end{array}$ & 0.21 & Vocal \\
\hline $\begin{array}{l}\text { Negative statements and complaints (Degree to which the message } \\
\text { sounds negative or includes complaints) }\end{array}$ & 0.21 & Verbal \\
\hline $\begin{array}{l}\text { Verbal and vocal involvement (Speaker describes personal } \\
\text { experiences or describe events in a personal and revealing way; speakers } \\
\text { seems vocally expressive) }\end{array}$ & -0.21 & Verbal and vocal \\
\hline Fidgeting (Object or self-fidgeting (undifferentiated)) & 0.16 & Visual \\
\hline Illustrators (Gestures that accompany speech) & -0.14 & Visual \\
\hline Facial pleasantness & -0.12 & Visual \\
\hline Note: Taken fram DePaub et al, (2003) & \\
\hline
\end{tabular}

Note: Taken from DePaulo et al. (2003)

Note: Negative $d$-scores indicate truth telling and positive $d$-scores indicate lying. 
Table 2. An overview of frequently mentioned nonverbal cues to deceit and their actual relationship with deception according to DePaulo et al. (2003) and believed relationships with deception according to Vrij (2008)

\begin{tabular}{|c|c|c|}
\hline Vocal cues & Actual relationship & Believed relationship \\
\hline $\begin{array}{l}\text { Hesitations (Use of speech fillers } \\
\text { e.g.,"ah", "um", "er", "uh" and } \\
\text { "hmmm") }\end{array}$ & .04 & $\mathrm{~L}$ \\
\hline $\begin{array}{l}\text { Speech errors (Grammatical } \\
\text { errors, word and/or sentence } \\
\text { repetition, false starts, sentence } \\
\text { change, sentence incompletions, } \\
\text { slips of the tongue, etc.) }\end{array}$ & .00 & $\mathrm{~L}$ \\
\hline High-pitch voice & .21 & $\mathrm{~L}$ \\
\hline $\begin{array}{l}\text { Speech rate (Number of spoken } \\
\text { words in a certain period of time) }\end{array}$ & .07 & - \\
\hline $\begin{array}{l}\text { Latency period (Period of silence } \\
\text { between question and answer) }\end{array}$ & .02 & - \\
\hline $\begin{array}{l}\text { Pause (Silent, filled or mixed } \\
\text { pauses) }\end{array}$ & .02 & $\mathrm{~L}$ \\
\hline \multicolumn{3}{|l|}{ Visual cues } \\
\hline $\begin{array}{l}\text { Gaze aversion (Looking away } \\
\text { from the conversation partner) }\end{array}$ & .03 & $\mathrm{~L}$ \\
\hline Smiles (Smiling and laughing) & .00 & - \\
\hline $\begin{array}{l}\text { Facial-fidgeting (Face touching } \\
\text { or rubbing hair) }\end{array}$ & .08 & $\mathrm{~L}$ \\
\hline $\begin{array}{l}\text { Self-fidgeting (Touching, } \\
\text { rubbing or scratching body or face) }\end{array}$ & -.01 & $\mathrm{~L}$ \\
\hline Fidgeting (Undifferentiated) & .16 & $\mathrm{~L}$ \\
\hline $\begin{array}{l}\text { Illustrators (Hand and arm } \\
\text { movements designed to modify } \\
\text { and/or supplement what is being said } \\
\text { verbally) }\end{array}$ & -.14 & - \\
\hline $\begin{array}{l}\text { Leg/foot movements } \\
\text { (Movements of legs and feet) }\end{array}$ & -.09 & $\mathrm{~L}$ \\
\hline $\begin{array}{l}\text { Posture shifts (Movements made } \\
\text { to change seating position) }\end{array}$ & .05 & $\mathrm{~L}$ \\
\hline $\begin{array}{l}\text { Head movements (Head nods } \\
\text { and head shakes) }\end{array}$ & -.02 & $\mathrm{~L}$ \\
\hline Eye blinks (Blinking of the eyes) & .07 & $\mathrm{~L}$ \\
\hline
\end{tabular}

Note: Positive $d$-scores indicate increase in liars and negative $d$-scores indicate decrease in liars, significant relationships are indicated in bold.

Note: 'L' means that people associate the cue with lying; '-' means that people do not think there is a relationship between the cue and deception 
Figure 1: Theories on nonverbal behavior and deception

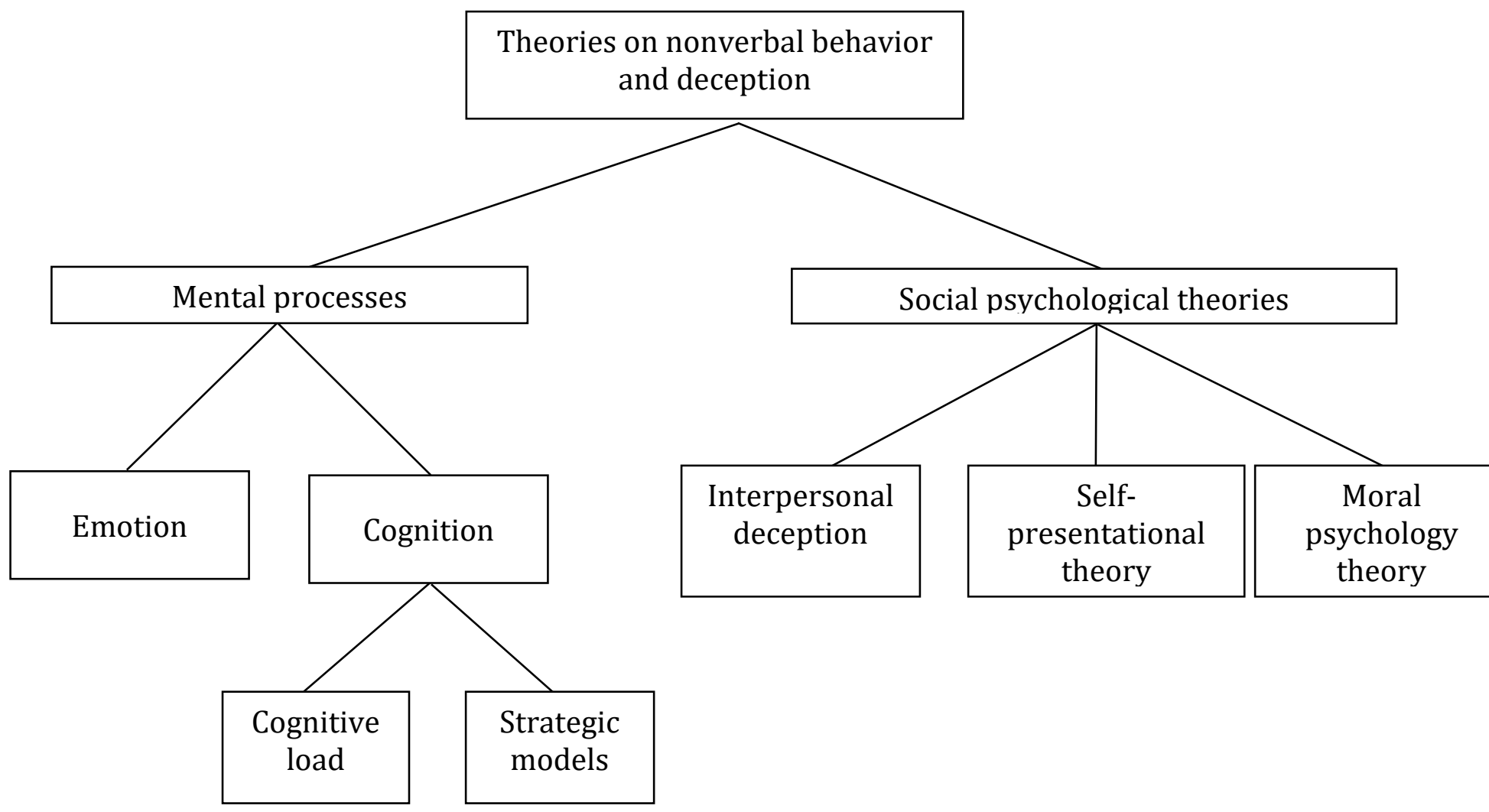


Box 1: Possible settings in which an analysis of nonverbal behavior could take place

\begin{tabular}{|c|c|c|c|c|}
\hline Type of setting & $\begin{array}{l}\text { Realistic } \\
\text { setting? }\end{array}$ & Example & $\begin{array}{l}\text { Nonverbal } \\
\text { analysis } \\
\text { required? }\end{array}$ & $\begin{array}{c}\text { Research } \\
\text { published? }\end{array}$ \\
\hline No interview and target does not speak & Yes & $\begin{array}{l}\text { Target observed } \\
\text { at an airport }\end{array}$ & Definitely & No \\
\hline An interview setting, but target does not speak & Yes & $\begin{array}{l}\text { Custodial } \\
\text { interview, } \\
\text { suspect is silent }\end{array}$ & Definitely & No \\
\hline $\begin{array}{c}\text { Target is interviewed outside the interview } \\
\text { room }\end{array}$ & Yes & $\begin{array}{c}\text { Target } \\
\text { approached at an } \\
\text { airport }\end{array}$ & $\begin{array}{c}\text { Not } \\
\text { necessarily }\end{array}$ & No \\
\hline $\begin{array}{l}\text { An interview setting, the target speaks, but no } \\
\text { interaction between interviewer/ target }\end{array}$ & No & Difficult to find & $\begin{array}{c}\text { Not } \\
\text { necessarily }\end{array}$ & $\begin{array}{l}\text { The vast } \\
\text { majority }\end{array}$ \\
\hline $\begin{array}{l}\text { An interview setting, the target speaks, } \\
\text { interaction between interviewer/ target, but no } \\
\text { background evidence }\end{array}$ & Yes & $\begin{array}{l}\text { Custom } \\
\text { interview, } \\
\text { Asylum } \\
\text { interview }\end{array}$ & $\begin{array}{c}\text { Not } \\
\text { necessarily }\end{array}$ & Little \\
\hline $\begin{array}{l}\text { An interview setting, the target speaks, } \\
\text { interaction between the interviewer/ target and } \\
\text { background evidence exists }\end{array}$ & Yes & $\begin{array}{l}\text { Typical police } \\
\text { interview of } \\
\text { suspect }\end{array}$ & No & Little \\
\hline
\end{tabular}

In Box 1 we list possible settings in which an analysis of nonverbal behavior could take place. We do not provide a complete list of all possible settings, but a list of settings that are relevant for the current overview. Each setting is assessed in terms of whether it is realistic (its operational relevance), whether it requires an analysis of nonverbal behavior, and the extent to which the setting has been addressed in nonverbal communication and deception research.

Box 1 allows us to draw several conclusions. First, an analysis of nonverbal behavior could, at least theoretically, take place in many different settings. However, second, it also shows that there are only a few settings for which an analysis of nonverbal behavior is absolutely essential. Basically, a nonverbal analysis is required only when the target does not speak. Third, the few settings in which an analysis of nonverbal behavior is required have not been addressed in research. Fourth, the vast majority of deception research has addressed a setting in which the target speaks (for a brief period), but where there is no real interaction between the target and the interviewer. This is not a realistic setting. In fact, we could not produce one single 
example that illustrates this setting. The overall conclusion is clear: Researchers should refocus and should examine nonverbal communication in settings where a nonverbal analysis is required. 